\title{
BÖLGESEL REKABETTE DIŞ TİCARETIN ÖNEMİ: KONYA ÖRNEĞİ
}

\author{
Ayşe ÇOBAN1 \\ Orhan ÇOBAN2 \\ Duygu BAYSAL KURT3 \\ M. Aykut USLU4
}

\section{ÖZET}

Bu çalışmada 2002-2013 dönemi dikkate alınarak bölgesel rekabet açısından önemli bir gelişme potansiyeline sahip olan Konya'nın dış ticareti analiz edilmiştir. Analiz sonuçlarına göre, Konya ili 104 farklı ürün ve 130 ülkeye yaptığ ihracatla İstanbul, İzmir ve Ankara'nın arkasında yer almaktadır. Konya sanayisinde 2002 y1lında 517 olan ihracat yapan firma sayısı 2013 yılında 1427'ye yükselmiştir. Benzer şekilde 2002 yılında 431 olan ithalatçı firma sayısı 2013 yılında 1106'ya yükselmiştir. Bu kapsamda 2013 yılında toplam ihracat 1,368 milyar dolar, toplam ithalat ise 1,226 milyar dolar olmuştur.

Taşıt araçları yan sanayisi ve makine teçhizat sektörü Konya imalat sanayisinin en önemli sektörlerinden birisidir. Söz konusu sektör 2013 yılı itibariyle 167 ülkeye çeşitli mamuller ihraç etmekte olup, 2013 y1lı ihracatı 204 milyon 461 bin dolar düzeylerinde gerçekleşmiştir. Bu sektörü 187 milyon 477 bin dolarlık ihracatla Makine ve Aksamları izlemektedir. Benzer şekilde ithalatta da birinci sırada imalat sanayi gelmektedir. 2013 yılında Konya'nın gerçekleştirdiği ithalatın \% 75'i İmalat sanayi tarafından gerçekleştirilmektedir. Tarım ve hayvancılık sektörünün toplam ithalattaki payı ise $\% 21$ dolaylarındadır. Konya ekonomisinin dış ticaret dengesi incelendiğinde ise 2008, 2009, 2010, 2012 ve 2013 yıllarında ekonominin rekabet gücünün yüksek olduğu görülmüştür.

Anahtar Kelimeler: Konya, Organize Sanayi Bölgesi, Bölgesel Rekabet, Dış Ticaret, İmalat Sanayi

Jel Kodlari: A10, F10, O18

\footnotetext{
${ }^{1}$ Öğr. Elemanı, Selçuk Üniversitesi, SBMYO, acoban@ @selcuk.edu.tr

${ }^{2}$ Prof. Dr., Selçuk Üniversitesi, İİBF, İktisat Bölümü, ocoban@ selcuk.edu.tr

${ }^{3}$ Arş. Gör., Selçuk Üniversitesi, İİBF, İktisat Bölümü, dbaysal@ selcuk.edu.tr

${ }^{4}$ YL Öğrencisi, Selçuk Üniversitesi, SBE, aykutuslu@ gmail.com
} 


\section{THE IMPORTANCE OF FOREIGN TRADE IN REGIONAL COMPETITION: THE CASE OF KONYA}

\section{ABSTRACT}

In this paper, by considering 2002-2013 period, foreign trade of Konya which has a significant development potential for regional competition was analyzed. According to the results, Konya is located behind to Istanbul, Izmir and Ankara with exports of 104 different products to 130 countries. When the number of exporting firms 517 was in Konya industry in 2002, it was 1427 in 2013. Similarly, when the number of importing firms was 431 in Konya industry in 2002, it was 1106 in 2013. In this context, while the total exports were 1.368 billion US dollars in 2013, imports were 1.226 billion US dollars during the same period.

Motor vehicles sub-industry and machinery-equipment sector is one of the most important sectors of the manufacturing industry in Konya. At present, this sector are exporting various products to 167 countries around the world, level of exports was actualized at 204 million 461 thousand US dollars in 2013. Machinery and Accessories industry is followed to this sector with 187 million 477 thousand dollars exports. Similarly, imports of the manufacturing industry were come first. In 2013, 75\% of the imports were carried out by the manufacturing industry in Konya. The share of the agriculture and livestock sectors is around $21 \%$ in total imports in 2013. When examining the trade balance of Konya economy, power of its competitiveness was seen to be high in 2008, 2009, 2010, 2012 and 2013.

Keywords: Konya, Organized Industrial Zone, Regional Competitiveness, Foreign Trade, Manufacturing Industry Jel Codes: A10, F10, O18

\section{GİRIŞ}

Dış ticaretin rekabet ve büyüme üzerine etkileri konusunda literatürde çok sayıda teori ve bu teorilerden hareketle yapılmış çalışmalar bulunmaktadır. Bunlardan bazıları, Klasikler tarafından geliştirilmiş olan mutlak üstünlük ve karşılaştırmalı üstünlük teorileri, faktör donatım teorisi, nitelikli işgücü teorisi, teknoloji açı̆̆ı teorisi, ürün dönemleri teorisi, tercihlerde benzerlik teorisi, ölçek ekonomileri teorisi ve monopolcü rekabet teorisidir. Burada söz konusu teorilerden Adam Smith tarafından geliştirilen mutlak üstünlük teorisi, David Ricardo tarafindan geliştirilen karşılaştırmalı üstünlük teorisi ile Eli Heckscher ve Bertil Ohlin tarafından geliştirilen faktör donatımı teorisi ön plana çıkan teorilerdir (Çoban, 2015: 420).

Keynes tarafından literatüre katılan teoride ise bir ekonomide milli gelirin oluşumuna katk1 sağlayan faktörler arasında ihracat ve ithalat sayılmaktadır. İhracat ve ithalat dış ticaret kavramı altında ele alınmaktadır. Dış ticaret üzerine yapılan ampirik çalışmalarda ihracat ve ithalat hacmine bağlı olarak şekillenen dış ticaret hacmini büyüme ve rekabet ile sıkı ilişki içinde olduğuna vurgu yapılmıştır. "Daha iyi ithalat yapmak için ihracat"ın önemine atıfta bulunan Keynesyen teori, ihracata bağlı olarak kaynakların daha etkin ve verimli kullanılabileceğini öne sürmektedir. Bu kapsamda yapılan bazı ampirik çalışmalarda ihracatın ithalata bağlı olduğu sonucuna ulaşılmıştır. İhracatta ortaya çıkacak başarı özellikle geri kalmış bölgelerde insanların yaşam düzeylerinin artırılmasına/iyileştirilmesine imkan sağlayacaktır. 20000'li yılardan sonra ortaya çıkan küreselleşme/liberalleşme eğilimleri uluslararası ticaret ve bölgesel rekabet gücü açısından ihracatın önemini daha da artırmıştır (Balassa, 1986; Sachs ve Warner, 1995; Frankel ve Romer, 1999; Coe ve Helpmann, 1995; Deng vd. 2009; Sun ve Heshmati, 2010; Mucuk ve Akgün, 2011).

Konya, Türkiye'nin yüz ölçümü bakımından en büyük ili ve nüfus açısından yedinci şehridir. 31 ilçeden oluşan Konya'da TÜİK'in 2013 verilerine göre 2.079.225 kişi yaşamaktadır. Trafik plaka numarası 42'dir. 1875'te kurulan Konya Belediyesi, 1987'de çıkarılan 3399 sayılı yasa gereğince "Büyükşehir" statüsüne kavuşmuş olup, 1989'dan beri belediye hizmetleri bu statüye göre yürütülmektedir. 2014'te 6360 sayılı kanun ile büyükşehir belediyesinin sınırları il mülki sınırları olmuştur (TÜIK, 2013: XIV).

Bu çalışmada bölgesel rekabet açısından önemli bir gelişme potansiyeline sahip olan Konya'nın dış ticaretinin analiz edilmesi amaçlanmıştır. Bu amaç doğrultusunda Konya'ya emsal olabilecek illere 
ilişkin veriler yardımıyla bir karşılaştırma yapılmıştır. Analizlerde 2002-2013 dönemine ilişkin veriler kullanılmış olup, söz konusu veriler TÜİK, Konya Sanayi Odası ve ilgili kuruluşların veri tabanlarından derlenmiştir.

Konya Anadolu Selçuklu Devleti ve Karamanoğulları Beyliğine başkentlik yapması ve coğrafi konumu itibariyle ekonomik açıdan sürekli canlı bir şehir olmuştur. Bu ekonomik hayatın canlılığının temelinde uçsuz bucaksız Konya ovasının varlığı sebebiyle tarımsal faaliyetler etkili olmuştur. Fakat son yıllarda sanayi alanında da büyük gelişmeler kaydedilmiştir. Bu durum Konya'nın Türkiye'de tahıl ambarı olma özelliğini değiştirerek, bir sanayi merkezi olma görünümü kazanmasına yol açmıştır.

İl düzeyinde bölgesel rekabetin en önemli aracı OSB'lerdir (Organize Sanayi Bölgeleri). Dünya'da ilk OSB uygulamaları 19. yy'da ABD'de başlamıştır. Türkiye'de Cumhuriyetin ilanından sonra sanayileşme politikaları kapsamında çeşitli çalışmalar yapılmış olmakla birlikte ilk OSB 1962 yılında Bursa'da faaliyete geçmiştir. Bursa' da kurulan OSB için Dünya Bankası kredisinden yararlanılmıştır. OSB uygulamaları için 2000 yılında 4562 Sayılı Organize Sanayi Bölgeleri Kanunu çıkarılmıştır. Konya'da ise I. Organize Sanayi Bölgesi 1967 yılında, II. Organize Sanayi Bölgesi 1976 y1lında ve son olarak da III. Organize Sanayi Bölgesi 1995 yılında kurulmuştur. 1 Mayıs 2006 tarihi itibariyle II. ve III. Organize Sanayi Bölgeleri, KOS (Konya Organize Sanayi Bölgesi) olarak birleştirilmiştir. IV. Organize Sanayi Bölgesi çalışmalarında ise gelinen son duruma göre, imar ve parselasyon çalışmaları tamamlanmış olup, İl Özel İdaresi tarafından onaylamıştır. IV. OSB alanının, Tapu Sicil Müdürlüğünden tapusu çıkarılmış olup, altyapıya ilişkin proje çalışmalarına devam edilmektedir. Konya sanayisi, yapısı itibariyle diğer ülke illeri sanayilerinden farklı olarak aynı anda birçok alanda faaliyet gösteren sektörleri içerisinde barındırmaktadır (Şahbaz, 2011; KTO, 2013; SOSB, 2016).

Konya'daki OSB'lerde faaliyet gösteren firmaların sektörel dağılımı Tablo-1'de özetlenmiştir.

Tablo- 1: Konya OSB'lerde Faaliyet Gösteren Firmaların Sektörel Dağılımı

\begin{tabular}{|c|l|c|c|c|c|c|}
\hline No & \multicolumn{1}{|c|}{ Sektör } & I.OSB & KOS & BÜSAN & Toplam & Oran \\
\hline 1 & Otomotiv Yan Sanayi & 21 & 72 & 67 & 160 & 0,16 \\
\hline 2 & Oto Dış Aksamı, Damper, Kara sör Sanayi & - & 8 & 9 & 17 & 0,02 \\
\hline 3 & Ziraat Alet Makineleri İmalat Sanayi & 14 & 22 & 14 & 50 & 0,05 \\
\hline 4 & Makine ve Yedek Parça İmalat Sanayi & 11 & 53 & 177 & 241 & 0,24 \\
\hline 5 & Döküm Sanayi & 12 & 24 & 15 & 51 & 0,05 \\
\hline 6 & Kağıt ve Ambalaj Sanayi & 5 & 5 & 7 & 17 & 0,02 \\
\hline 7 & Sondaj Boru ve Sulama Sistemleri & 10 & - & - & 10 & 0,01 \\
\hline 8 & Plastik, Boya ve Kimya Sanayi & 13 & 25 & 28 & 66 & 0,07 \\
\hline 9 & İşaat Malzemeleri Sanayi & 5 & 15 & 45 & 65 & 0,07 \\
\hline 10 & Deri ve Tekstil Ürünleri İmalat Sanayi & 9 & - & 7 & 16 & 0,02 \\
\hline 11 & Değirmen Makineleri İmalat Sanayi & 9 & 4 & - & 13 & 0,01 \\
\hline 12 & Demir Dışı Metaller (Alüminyum Sanayi) & 7 & 52 & 16 & 75 & 0,08 \\
\hline 13 & Gıda Sanayi & - & 15 & 38 & 53 & 0,05 \\
\hline 14 & Ağaç, Mobilya ve Orman Ürünleri & - & 3 & 17 & 20 & 0,02 \\
\hline 15 & Diğer & 39 & 68 & 26 & 133 & 0,13 \\
\hline & Toplam & 155 & 366 & 466 & 987 & 1 \\
\hline
\end{tabular}


Kaynak: KTO, 2013.

Tablo-1'e göre Konya'daki OSB'lerde toplam 987 firma faaliyet göstermektedir. Bu kapsamda söz konusu firmaların 466 tanesi BÜSAN OSB'de, 366 tanesi KOS'da ve 155 tanesi de I. OSB'de yer almaktadır. Sektörel açıdan ele alındığında firmalardan \% 24'ünün Makine ve Yedek Parça İmalat Sanayinde faaliyet gösterdiği tespit edilmiştir. Bu sektörü \% 16'llk payla Otomotiv Yan Sanayii, \%8'lik payla Demir Dışı Metaller, \% 7'lik payla Plastik Boya ve Kimya Sanayii ile İnşaat Malzemeleri Sanayii takip etmektedir. BU kapsamda Diğer başlığı altında sınıflandırılan sektörlerin payı ise $\% 13$ 'dür.

\section{KONYA EKONOMISININ İHARACAT VE ITHALATI}

Konya, 104 farklı ürün ve 130 ülkeye yaptığı ihracatla Türkiye'de İstanbul, İzmir ve Ankara'nın hemen arkasından ihracatta çeşitlilik bakımında 4. sırada yer almaktadır. Bu durumda Konya'nın ihracat potansiyelinin büyüklüğü hakkında fikir sahibi olmamıza yardım edecektir. İhraç edilen ürün fazlalı̆̆ ihracat yapma potansiyelini arttırmaktadır.

Konya'nın ihracatının artmasındaki en büyük etkenlerden birisi de gerçekleştirilen uluslararası fuarlardır. Konya Ticaret Odası tarafından 1999 yılında kurulan KTO-TÜYAP Uluslararası Fuar Merkezi'nde düzenlenen çeşitli fuarlarda her yıl 500 bine yakın sektör temsilcisi bir araya gelmektedir ve bu da Konya'nın ihracatının artmasında etkili olmaktadır. Zamanla Konya bir fuar ve kongre merkezi haline gelmektedir. KTO - TUYAP Uluslararası Fuar Merkezinde Ayakkabı Yan Sanayi ve Moda; Yapı; Doğalgaz; Makine; Tarım; Gıda; Ambalaj; Plastik; Kauçuk; Ev Ve Yaşam; Güzellik; Kitap; Dekorasyon; Otomotiv gibi alanlarda her yıl yaklaşık 12 uluslararası fuar düzenlenmektedir. KTO - TÜYAP Fuar Alanı'nda gerçekleştirilen uluslararası fuarlarla şehrimizin sanayi ürünleri ve ticareti en iyi şekilde tanıtılarak iş adamlarımızın iş bağlantıları kurmaları ve pazar paylarını genişletmeleri sağlanmaktadır. Ayrıca bölgeye ve Konya’ya bu amaçla hizmet edecek bir Bölgesel Dış Ticaret Merkezi kurulması ve ihracat yapmak isteyenlere her türlü desteğin sağlanmas1 planlanmaktadır (Altay, 2013: 23).

\section{1. İhracat Analizi}

Konya ekonomisinin ihracat analizi için ihracatçı firma sayılarından hareketle toplam ihracat değeri, ihracatın sektörel ve ülkelere göre dağılımının yanı sıra Türkiye ekonomisi içerisindeki yeri dikkate alınmıştır.

Şekil-1'de Konya'daki 2002-2013 yılları arasındaki ihracatçı firma sayıları ve ihracat değerleri yer almaktadir. 
Şekil- 1: Konya'da İhracatçı Firma Sayıları ve İhracat Değeri (Bin Dolar)

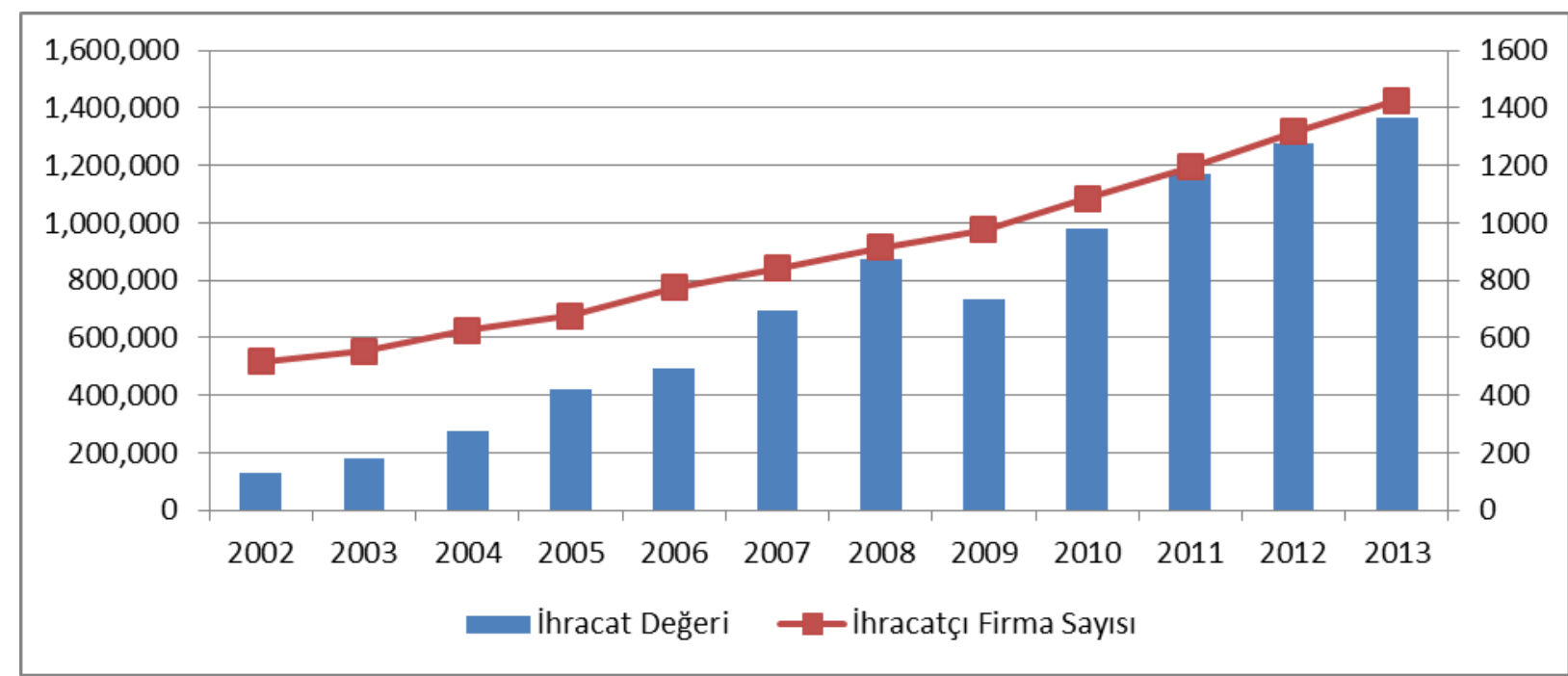

Kaynak: Kadeş, 2014; KTO, 2014; TÜİK, 2014.

Şekil-1 incelendiğinde ele alınana dönemde hem ihracatçı firma sayısının arttığ ve buna bağlı olarak Konya ekonomisinin ihracat değerinde bir artış ortaya çıktı̆̆ 1 görülmektedir. Buna göre 2002 yılında 517 olan ihracatçı firma sayısı, 2006 yılında 774'e, 2010 yılında 1086'ya ve son olarak 2013 yılında 1427'ye yükselmiş̧ir. Firma sayısındaki artışa paralel olarak Konya ekonomisinin 2002 yılında 130 milyon dolar olan ihracat değeri, 2006 yılında 493 milyon dolara, 2010 y1lında 979 milyon dolara ve son olarak 2013 y1lında 1,4 milyar dolara yükselmiştir.

Tablo-2 yardımıyla düzenlenen ihracatın sektörel dağılımı ise Tablo-3'de düzenlenmiştir.

Tablo- 2: Konya'da İhracatın Sektörel Dağılımı (Bin Dolar)

\begin{tabular}{|c|c|c|c|c|c|}
\hline Y1llar & $\begin{array}{c}\text { Tarım ve } \\
\text { Ormancilık }\end{array}$ & $\begin{array}{c}\text { Madencilik ve Taş } \\
\text { Ocakçılığ }\end{array}$ & $\begin{array}{c}\text { İmalat } \\
\text { Sanayi }\end{array}$ & $\begin{array}{c}\text { Toptan ve } \\
\text { Perakende Ticaret }\end{array}$ & Toplam \\
\hline 2002 & 4752 & 451 & 124646 & 111 & 129959 \\
\hline 2003 & 6771 & 392 & 171132 & 744 & 179039 \\
\hline 2004 & 4644 & 497 & 267779 & 2636 & 275556 \\
\hline 2005 & 4525 & 216 & 411495 & 375 & 419985 \\
\hline 2006 & 6928 & 597 & 482635 & 3372 & 493532 \\
\hline 2007 & 24539 & 917 & 657003 & 3398 & 694111 \\
\hline 2008 & 33631 & 7327 & 827956 & 2309 & 871223 \\
\hline 2009 & 26091 & 4832 & 703347 & 1727 & 735997 \\
\hline 2010 & 43820 & 19456 & 913592 & 1917 & 978785 \\
\hline 2011 & 67735 & 20134 & 1077200 & 3527 & 1168597 \\
\hline 2012 & 76286 & 8959 & 1186609 & 3769 & 1275623 \\
\hline 2013 & 77308 & 11494 & 1274849 & 4414 & 1368078 \\
\hline
\end{tabular}

Kaynak: TüíK, 2015.

Tablo-2'de yer alan verilere göre Konya ihracatında en önemli sektör imalat sanayidir. 2002 y1lında yaklaşı 130 milyon dolarlık ihracatın 125 milyon dolarlık kısmını karşılayan sektörün 2006 yılı ihracatı 2006 y1lında 483 milyon dolara, 2010 yılında 914 milyon dolara ve son olarak 2013 yılında 1,3 milyar dolara çıkmıştır. 2013 yılı verileri dikkate alındığında Konya İmalat Sanayii toplam 
ihracatın \%93'ünü gerçekleştirmiştir. İmalat sanayini tarım ve ormancılık, madencilik ve taş ocakçı1lı̆ ile toptan ve perakende ticaret izlemiştir.

Tablo-3'de düzenlenen veriler ayrıntılı olarak analiz edildiğinde, Tablo-4'de yer alan verilere ulaşılmaktadır.

Tablo- 3: Konya'da İhracatın Ana Sektörlere Göre Dağılımı (2013) (Bin Dolar)

\begin{tabular}{|c|c|c|c|}
\hline & & Değer & $\%$ \\
\hline 1 & Taşıt Araçları ve Yan Sanayi & 287485 & 23 \\
\hline 2 & Makine ve Aksamları & 283027 & 16 \\
\hline 3 & Hububat, Bakliyat, Yağlı Tohumlar ve Mamulleri & 193576 & 11 \\
\hline 4 & Demir ve Demir Dışı Metaller & 131697 & 8 \\
\hline 5 & Kimyevi Maddeler ve Mamulleri & 103652 & 7 \\
\hline 6 & Su Ürünleri Ve Hayvancılık Mamulleri & 90669 & 3 \\
\hline 7 & Maden ve Metaller & 38918 & 2 \\
\hline 8 & Savunma Ve Havacıllk Sanayii & 32565 & 2 \\
\hline 9 & Çelik & 26578 & 2 \\
\hline 10 & Meyve Sebze Mamulleri & 22937 & 2 \\
\hline 11 & Ağaç Mamulleri ve Orman Ürünleri & 22370 & \\
\hline
\end{tabular}

Kaynak: TiM, 2015.

Tablo-3 incelendiğinde 2013 yılında Konya ekonomisinde Taşı Araçları ve Yan Sanayisinin 287 milyon dolarlık değer ile ilk sırada yer almıştır. Bu sektörü 283 milyon dolar ile Makine ve Aksamları, 193 milyon dolar ile Hububat, Bakliyat, Yağı Tohumlar ve Mamulleri, 132 milyon dolarla Demir ve Demir Dışı Metaller, 104 milyon dolarla Kimyevi maddeler ve Mamulleri takip etmiştir. Bu verilere göre Taşıt Araçları ve Yan Sanayisi toplam ihracatın \%23'ünü, Makine ve Aksamları sektörü de benzer şekilde \%23’ünü, Hububat, Bakliyat, Yağglı Tohumlar ve Mamulleri \%16'sını ve Demir ve Demir Dışı Metaller sektörü ise \%11'ini gerçekleştirmiştir.

Konya'nın ihracatının ülkeler itibariyle dağılımı ise Tablo-4'de özetlenmiştir.

Tablo- 4: Konya'nın İhracatında İlk 10 Ülke

\begin{tabular}{|c|c|c|c|c|c|}
\hline \multicolumn{2}{|c|}{2002} & \multicolumn{2}{c|}{2008} & \multicolumn{2}{c|}{2013} \\
\hline Ülkeler & $\begin{array}{c}\text { İhracat } \\
(\text { Dolar }\end{array}$ & Ülkeler & İhracat (Dolar) & Ülkeler & İhracat (Dolar) \\
\hline Almanya & 11138795 & İtalya & 65694418 & Irak & 236481168 \\
\hline Misır & 6833731 & Yunanistan & 55314905 & Almanya & 81552145 \\
\hline Rusya Federasyonu & 5794335 & Irak & 52206994 & $\begin{array}{c}\text { Rusya } \\
\text { Federasyonu }\end{array}$ & 55774691 \\
\hline ABD & 5269907 & Almanya & 50111903 & İran & 49800487 \\
\hline Fransa & 4680282 & Rusya Federasyonu & 48038237 & Libya & 49270773 \\
\hline Hollanda & 4629994 & İran & 35370667 & Suudi Arabistan & 46882317 \\
\hline Suudi Arabistan & 3905534 & Suriye & 33991737 & Misir & 37572453 \\
\hline Avusturya & 3613011 & Libya & 27466317 & Yunanistan & 37379600 \\
\hline İngiltere & 3483940 & ABD & 27183283 & ABD & 35408180 \\
\hline Azerbaycan & 3384756 & BAE & 25062776 & İngiltere & 33732858 \\
\hline TOPLAM & 129959367 & & 871222794 & & 1368078672 \\
\hline
\end{tabular}

Kaynak: TÜİK, 2015. 
Tablo-4'te en fazla ihracat yapılan ülkelerin sıralamaları yıllar itibariyle değişmektedir. Bunun en önemli nedeni, son yıllarda ülke-bölge düzeyinde yaşanan siyasi ve ekonomik istikrarsızlıklardır. Konya ekonomisinde üretilen ürünlerin çok çeşitli olmasından dolayı Konya dünyada birçok ülkeye ihracat yapabilmektedir. 2002 yılında Konya'nın ihracatında ilk sırada 11 Milyon dolar ile Almanya yer alırken 1,554 dolar ile Tanzanya son sırada yer almıştır. 2008 yılında ise en fazla ihracat yaklaşı 66 milyon dolarla İtalya'ya yapılırken, Kongo Demokratik Cumhuriyeti 11,520 dolar ile son sirada yer almıştır. Son olarak 2013 verilerine göre dünyada 167 ülkeye ihracat yapan Konya ekonomisini en fazla ihracat yaptığı ülke 236 milyon dolar ile Irak olmuştur. Bu dönemde Faroe Adaları 481 bin dolarlık rakam ile son sırada yer almıştır. Tabloda yer alan rakamlara göre özellikle 2008 yılından itibaren Avrupa'daki ekonomik kriz sebebiyle Konya ekonomisi Ortadoğu ve Asya ülkelerine yönelmiştir. Bu durum ülke çeşitliliğini artırmıştır.

Konya ilinin ihracatı emsal olarak kabul edilen Eskişehir, Kayseri, Adana, Denizli, Gaziantep ve Kahramanmaraş gibi şehirlerle karşılaştırıldığında Tablo-5'deki verilere ulaşılmıştır.

Tablo- 5: Konya ve Benzer İllerin İhracatları (Dolar)

\begin{tabular}{|c|c|c|c|c|c|c|c|}
\hline Y1llar & Adana & Denizli & Eskişehir & Gaziantep & K. Maraş & Kayseri & Konya \\
\hline 2002 & 461040 & 680541 & 151065 & 619536 & 351569 & 110305 & 129959 \\
\hline 2003 & 565281 & 866083 & 179607 & 866153 & 465104 & 138732 & 179039 \\
\hline 2004 & 816249 & 1196291 & 214078 & 1295292 & 205874 & 639617 & 275556 \\
\hline 2005 & 883833 & 1415355 & 268761 & 1652554 & 229108 & 702969 & 419985 \\
\hline 2006 & 958987 & 1635422 & 352089 & 1857722 & 286321 & 751660 & 493532 \\
\hline 2007 & 1166028 & 2010063 & 507089 & 2447656 & 325518 & 977544 & 694111 \\
\hline 2008 & 1304024 & 2196710 & 611317 & 3237061 & 379376 & 1122165 & 871223 \\
\hline 2009 & 1135887 & 1587500 & 557848 & 2952993 & 430775 & 964320 & 735997 \\
\hline 2010 & 1352306 & 2127923 & 633981 & 3518434 & 531687 & 1164317 & 978786 \\
\hline 2011 & 1756356 & 2639582 & 766925 & 4759952 & 711945 & 1469400 & 1168598 \\
\hline 2012 & 1914550 & 2622545 & 924830 & 5579875 & 753878 & 1582410 & 1275626 \\
\hline 2013 & 1916196 & 2741457 & 829423 & 6515194 & 862603 & 1765892 & 1368078 \\
\hline
\end{tabular}

Kaynak: TÜIK, 2015.

Tablo-5 incelendiğinde ele alınan dönemde Konya'nın ihracatı 9,53 kat artmıştır. Bu bağlamda söz konusu ihracat Adana'da 3,16 kat, Denizli'de 3,03 kat, Eskişehir'de 4,49 kat, Gaziantep'te 9,52 kat, Kahramanmaraş'ta 1,45 kat ve Kayseri'de 15,01 kat artmıştır.

Konya ekonomisinin Türkiye ekonomisinin geneli ile karşılaştırma yapıldığında Tablo-6'de yer alan sonuçlara ulaşılmıştır. 
Tablo- 6: Konya'nın Türkiye İhracatındaki Payı (Bin Dolar)

\begin{tabular}{|l|c|c|c|}
\hline Y1llar & Türkiye & Konya & $\begin{array}{c}\text { Konya'nın Türkiye İhracatındaki Pay1 } \\
(\%)\end{array}$ \\
\hline 2002 & 36059089 & 129959 & 0,36 \\
\hline 2003 & 47252836 & 179039 & 0,38 \\
\hline 2004 & 63167153 & 275556 & 0,44 \\
\hline 2005 & 73476408 & 419985 & 0,57 \\
\hline 2006 & 85534676 & 493532 & 0,58 \\
\hline 2007 & 107271750 & 694111 & 0,65 \\
\hline 2008 & 132027196 & 871223 & 0,66 \\
\hline 2009 & 102142613 & 735997 & 0,72 \\
\hline 2010 & 113883219 & 978786 & 0,86 \\
\hline 2011 & 134906869 & 1168598 & 0,87 \\
\hline 2012 & 152461737 & 1275626 & 0,84 \\
\hline 2013 & 151802637 & 1368078 & 0,90 \\
\hline
\end{tabular}

Kaynak: TÜIK, 2015.

Tablo-6'ya göre Konya'nın Türkiye ihracatı içerisindeki payının her geçen yıl yükseldiği tespit edilmiştir. Buna göre 2002 y1lında \% 0,36 olan söz konusu oran, 2006 yılında \%0,58, 2010 y1lında \% 0,86 ve son olarak 2013 yılında \% 0,90 olmuştur.

İllerin ihracat rakamları ve Türkiye ihracatındaki payları ise Tablo-8' de yer almaktadır.

Tablo- 7: Türkiye’de İllerin İhracatları ve Toplam İhracattaki Payları (2013)

\begin{tabular}{|c|c|c|c|}
\hline Sira & İler & İhracat (Bin Dolar) & Türkiye İhracatındaki Pay1 (\%) \\
\hline 1 & İstanbul & 78719221 & 51,86 \\
\hline 2 & İzmir & 9484108 & 6,25 \\
\hline 3 & Kocaeli & 9105919 & 6 \\
\hline 4 & Bursa & 8927814 & 5,88 \\
\hline 5 & Ankara & 7672284 & 5,05 \\
\hline 6 & Gaziantep & 6515194 & 4,29 \\
\hline 7 & Denizli & 2741457 & 1,81 \\
\hline 8 & Sakarya & 2250874 & 1,48 \\
\hline 9 & Hatay & 2097846 & 1,38 \\
\hline 10 & Adana & 1916196 & 1,26 \\
\hline 14 & Konya & 1368079 & 0,90 \\
\hline
\end{tabular}

Kaynak: TÜiK, 2015.

Tablo-7'ye göre Türkiye'nin ihracatında İstanbul 79 milyar dolarlık ihracat ve \%51,86'pay ile ilk sırada yer almaktadır. İstanbul'u 9,5 milyar dolarla İzmir, 9,1 milyar dolarla Kocaeli, 8,9 milyar dolarla Bursa ve 7,7 milyar dolarla Ankara takip etmektedir. Böylece Konya ekonomisi yaklaşık 1,4 milyar dolarlık ihracat değeri ile Türkiye'nin toplam ihracatının \% 0,9'unu gerçekleştirmiştir. 


\section{2. İthalat Analizi}

Konya'daki 2002-2013 yılları arasındaki ithalatçı firma sayıları ve ithalat değerleri Şekil-2 yardımıyla özetlenmiştir.

Şekil- 2: Konya'da İthalatçı Firma Sayıları ve İthalat Değeri (Bin Dolar)

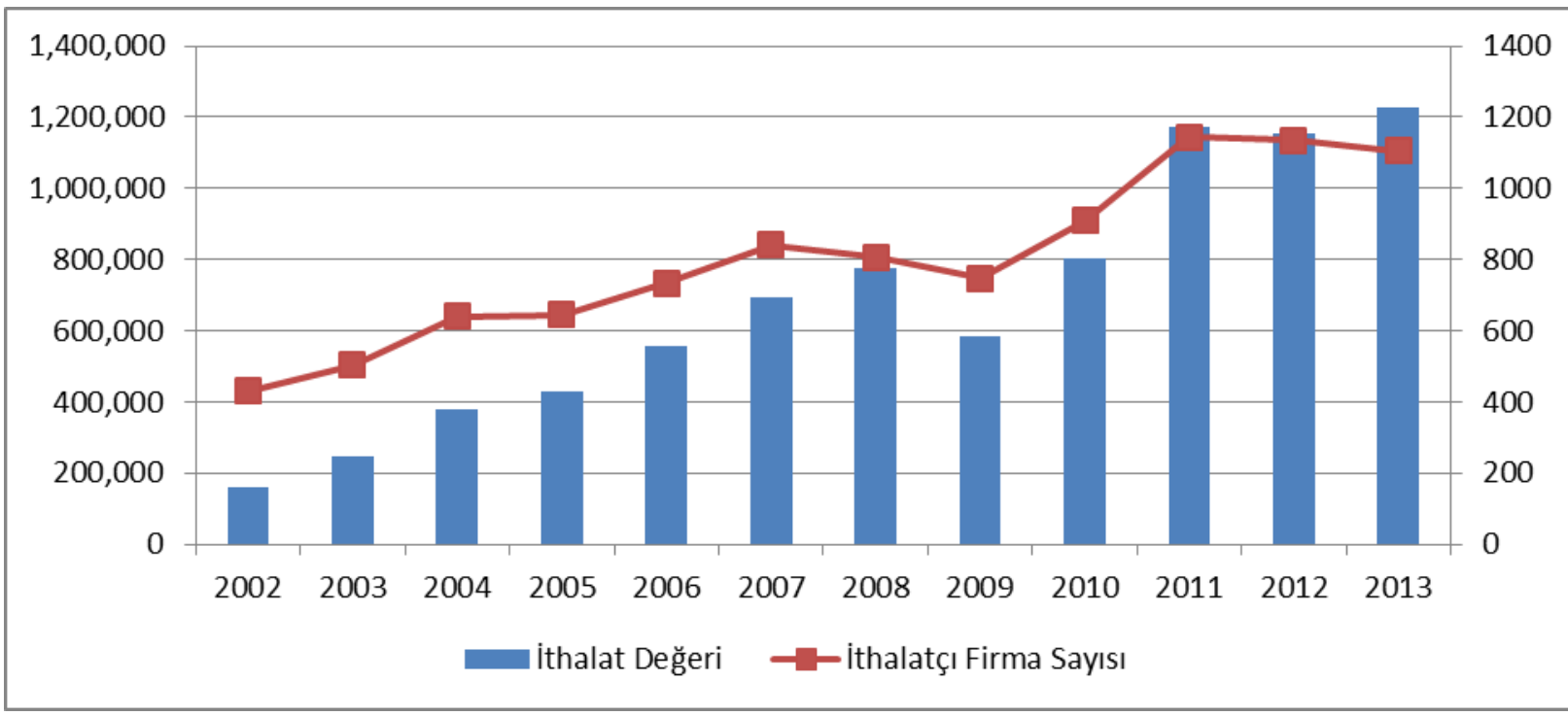

Kaynak: BUTSO, 2013; TÜIKK, 2015.

Şekil-2'de 2002 yılında 431 olan ithalatçı firma sayısı sürekli olarak artmış; 2006 yılında 733'e, 2010 yılında 909'a ve son olarak 2013 yılında 1106'ya yükselmiştir. İthalatçı firma sayısındaki söz konusu artışa paralel olarak ithalat değeri de sürekli olarak artmış; 2002 yılında 161 milyon dolar olan ithalat, 2006 y1lında 556 milyon dolara, 2010 yılında 802 milyon dolara ve son olarak 2013 yılında 1,23 milyar dolara yükselmiştir. Konya'da ithalatın sektörel dağılımı Tablo-8'de gösterilmektedir.

Tablo- 8: Konya'da İthalatın Sektörel Dağılımı (Bin Dolar)

\begin{tabular}{|c|c|c|c|c|c|}
\hline Yillar & $\begin{array}{c}\text { Tarım ve } \\
\text { Ormancılık }\end{array}$ & $\begin{array}{c}\text { Madencilik ve Taş } \\
\text { Ocakçılığ } 1\end{array}$ & $\begin{array}{c}\text { İmalat } \\
\text { Sanayi }\end{array}$ & $\begin{array}{c}\text { Toptan ve } \\
\text { Perakende Ticaret }\end{array}$ & Toplam \\
\hline 2002 & 12742912 & 2021923 & 145253292 & 1545979 & 161564106 \\
\hline 2003 & 12870459 & 1889293 & 228376608 & 1781948 & 244921044 \\
\hline 2004 & 29550339 & 2494222 & 339742242 & 5783024 & 377698390 \\
\hline 2005 & 11212651 & 3312695 & 406336168 & 6159553 & 427021067 \\
\hline 2006 & 11212651 & 3312695 & 535139838 & 6159553 & 555828780 \\
\hline 2007 & 86856371 & 1627080 & 600319465 & 6787052 & 695624775 \\
\hline 2008 & 173890526 & 14904666 & 578205569 & 8399411 & 775418185 \\
\hline 2009 & 98624322 & 24889825 & 455279617 & 4670110 & 583483069 \\
\hline 2010 & 134261603 & 3470254 & 657840398 & 7248433 & 802841756 \\
\hline 2011 & 206891020 & 4878909 & 949795309 & 8994789 & 1170863856 \\
\hline 2012 & 214483849 & 4858017 & 924053816 & 9193977 & 1153774350 \\
\hline 2013 & 262044596 & 38096583 & 939750366 & 9798134 & 1249700244 \\
\hline
\end{tabular}

Kaynak: TÜİK, 2015. 
Tablo-8'e göre Konya'da ihracatta olduğu gibi ithalatta da ilk sirada imalat sanayisi gelmektedir. 2002 yılında 162 milyon dolarlık toplam ithalatın 145 milyon dolarlık kısmı İmalat Sanayii tarafindan yapılmıştır. Söz konusu rakam 2006 yılında 535 milyon dolara, 2010 yılında 658 milyon dolara ve son olarak 2013 yılında 940 milyon dolara yükselmiştir. Bu rakamlara göre imalat sanayinin toplam ithalat içerisindeki payı 2002 yılında \% 88'düzeylerinden 2006 yılında \% 96'ya çıkmış, 2010 yılında \%81'e ve son olarak 2013 yılında \% 75'e düşmüştür. 2013 yılı verilerini dikkate aldığımızda, İmalat Sanayini \%21'lik payla Tarım ve Ormancılık ve \%3'lük payla Madencilik ve Taş Ocakçılığı takip etmiştir.

Konya ekonomisinin ithalatının ülkelere göre dağılımı ise Tablo-9'da yer almaktadır.

Tablo- 9: Konya'nın İthalatında İlk 10 Ülke

\begin{tabular}{|c|c|c|c|c|c|}
\hline \multicolumn{2}{|c|}{2002} & \multicolumn{2}{c|}{2008} & \multicolumn{2}{c|}{2013} \\
\hline Ülkeler & İthalat (Dolar) & Ülkeler & İthalat (Dolar) & Ülkeler & İthalat (Dolar) \\
\hline Rusya Federasyonu & 18913283 & $\begin{array}{c}\text { Rusya } \\
\text { Federasyonu }\end{array}$ & 93875969 & $\begin{array}{c}\text { Rusya } \\
\text { Federasyonu }\end{array}$ & 168563917 \\
\hline Almanya & 17682761 & Almanya & 68558675 & Çin & 137505393 \\
\hline Çin & 16608143 & Çin & 68483701 & Almanya & 106005001 \\
\hline İtalya & 15485825 & Kazakistan & 50181031 & İtalya & 70211534 \\
\hline Ukrayna & 12614444 & İtalya & 48620758 & Kazakistan & 49399890 \\
\hline Romanya & 12427233 & Tayvan & 34429515 & Suudi Arabistan & 48620464 \\
\hline Avusturya & 5561171 & Belçika & 28647131 & Tayvan & 43695018 \\
\hline ABD & 5537781 & Ukrayna & 27258129 & Hollanda & 39710602 \\
\hline Japonya & 5124630 & ABD & 23480335 & Hindistan & 33628846 \\
\hline Litvanya & 4949685 & Hollanda & 22722229 & Güney Kore & 27509037 \\
\hline TOPLAM & 161564106 & & 775418185 & & 1249700244 \\
\hline
\end{tabular}

Kaynak: TÜiK, 2015.

Tablo-9'a göre ülke sıralamalarında değişiklikler olmakla birlikte ilk 4 ülkenin yerleri değişmemiştir. Buna göre 2002, 2008 ve 2013 yıllarında Konya ekonomisinin ithalatında ilk sıray Rusya Federasyonu almıştır. Bu ülkeyi 2002, 2008 yıllarında Almanya ve Çin, 2013 yılında ise Çin ve Almanya izlemiştir. 2008 krizine bağlı özellikle Avrupa piyasalarından ithalat yapan Konya'nın bu kriz sonrası tedarikçileri değişmiş ve 2013 yılı verilerine göre Asya'ya ve Uzakdoğu'ya yönelmiştir. Bu bağlamda 2002 yılında sadece Çin ve Japonya'dan ithalat yapılırken, 2013 yılında bu ülkelere Hindistan, Güney Kore, Tayvan, Suudi Arabistan ve Kazakistan eklenmiştir.

Konya ilinin ithalatı emsal olarak kabul edilen şehirlerle karşılaştırıldığında Tablo-10'daki verilere ulaşılmıştır. 
Tablo- 10: Konya ve Benzer İllerin İthalatları (Dolar)

\begin{tabular}{|c|c|c|c|c|c|c|c|}
\hline Y1llar & Adana & Denizli & Eskişehir & Gaziantep & K.Maraş & Kayseri & Konya \\
\hline 2002 & 618770 & 319344 & 137510 & 658227 & 201323 & 408115 & 161564 \\
\hline 2003 & 844900 & 476042 & 211040 & 1000182 & 264684 & 494161 & 244921 \\
\hline 2004 & 1125065 & 489713 & 271327 & 1332130 & 333756 & 818622 & 377698 \\
\hline 2005 & 1265050 & 720875 & 262820 & 1686155 & 356717 & 913418 & 427021 \\
\hline 2006 & 1441273 & 1012591 & 325580 & 1846300 & 435827 & 1095115 & 555829 \\
\hline 2007 & 1918628 & 1376425 & 388425 & 2269084 & 812307 & 1291328 & 695625 \\
\hline 2008 & 2151647 & 1634676 & 511848 & 2793357 & 531429 & 1387750 & 775418 \\
\hline 2009 & 1692782 & 1146484 & 413332 & 2128417 & 545686 & 1001632 & 583483 \\
\hline 2010 & 2228986 & 1730895 & 615195 & 3430219 & 806061 & 1449376 & 802426 \\
\hline 2011 & 2974779 & 2262650 & 627502 & 4723312 & 1188472 & 1724364 & 1170864 \\
\hline 2012 & 3046332 & 2262295 & 645143 & 5053993 & 1037028 & 1589201 & 1153774 \\
\hline 2013 & 2747149 & 2350060 & 700657 & 6658020 & 1157102 & 1755165 & 1226470 \\
\hline
\end{tabular}

Kaynak: TÜiK, 2015.

Tablo-10'a göre ele alınan dönemde en yüksek ithalat artışı 9,12 kat ile Gaziantep'te gerçekleşmiştir. Gaziantep'i sırasıyla; Konya 6,59 kat, Denizli 6,36 kat, Kahramanmaraş 4,75 kat, Eskişehir 4,1 kat, Adana 3,44 kat ve Kayseri ili 3,3 katlık bir artışla takip etmektedir.

\section{KONYA EKONOMISINIIN DIŞ TICCARET DENGESİ}

Mikro veya makro ölçekte bir sektörün veya bir ekonominin rekabet gücünün veya performansının ölçümünde dış ticaret dengesi oldukça önemlidir. Tablo-11'de Konya ekonomisinin 2002-2013 döneminde dış ticaret analizinin özeti yer almaktadır.

Tablo- 11: Konya'nın Dış Ticaret Dengesi (Bin Dolar)

\begin{tabular}{|c|c|c|c|c|}
\hline Yillar & İhracat Değeri & İthalat Değeri & Diş Ticaret Dengesi & İhracat Değeri/İthalat Değeri \\
\hline 2002 & 129959 & 161564 & -31605 & 0,80 \\
\hline 2003 & 179039 & 244921 & -65882 & 0,73 \\
\hline 2004 & 275556 & 377698 & -102142 & 0,73 \\
\hline 2005 & 419985 & 427021 & -7036 & 0,98 \\
\hline 2006 & 493532 & 555829 & -62297 & 0,89 \\
\hline 2007 & 694111 & 695625 & -1514 & 0,99 \\
\hline 2008 & 871223 & 775418 & 95805 & 1,12 \\
\hline 2009 & 735997 & 583483 & 152514 & 1,26 \\
\hline 2010 & 978786 & 802426 & 176360 & 1,22 \\
\hline 2011 & 1168598 & 1170864 & -2266 & 0,99 \\
\hline 2012 & 1275626 & 1153774 & 121851 & 1,11 \\
\hline 2013 & 1368078 & 1226470 & 141608 & 1,12 \\
\hline
\end{tabular}

Kaynak: TÜiK, 2015.

Tablo-11'e göre 2002 y1lında yaklaşı 130 milyon dolar olan toplam ihracat değeri yıllar itibariyle sürekli olarak artmış; 2006 yılında 494, 2010 yılında 979 ve son olarak 2013 yllında ise 1,37 milyar dolara yükselmiştir. Benzer şekilde Konya'nın toplam ithalatı da ele alınan dönemde genel anlamda artmış; 2002 yılında 161 milyon dolar olan toplam ithalat, 2006 y1lında 556, 2010 yılında 802 ve son olarak 2013 yılında 1,22 milyar dolar olarak gerçekleşmiştir. Söz konusu verilerden hareketle hesaplanan dış ticaret dengesi göz önüne alındığında, bazı yıllarda dış ticaret dengesinin fazla, bazı 
yıllarda ise açık verdiği belirlenmiştir. Buna göre 2008, 2009, 2010, 2012 ve 2013 yıllarında ihracatın ithalatı karşılama oranı 1'in üzerinde, diğer yılar ise altında kalmıştır. Değerin 1'in üzerinde olması ilgili ekonominin rekabet gücünün yüksek, altında olması ise düşük olduğuna işaret etmektedir.

\section{SONUÇ}

$\mathrm{Bu}$ çalışmada bölgesel rekabet açısından önemli bir gelişme potansiyeline sahip olan Konya'nın dış ticareti incelenmiştir. Ayrıca, Konya'ya emsal olabilecek illere ilişkin veriler yardımıyla bir karşılaştırma yapılmıştır. Analizlerde 2002-2013 dönemine ilişkin veriler kullanılmış olup, söz konusu veriler TÜIK, Konya Sanayi Odası ve ilgili kuruluşların veri tabanlarından yararlanılmıştır.

Analiz sonuçlarına göre Konya'daki OSB'lerde toplam 987 firmanın faaliyet gösterdiği tespit edilmiştir. Bu firmalardan \% 24'ü Makine ve Yedek Parça İmalat Sanayiinde, \% 16'sı Otomotiv Yan Sanayii ve \% 3’ü ise diğer sektörlerde faaliyet göstermektedir.

Konya ilinin ihracat performansı analiz edildiğinde; 2002 yılında 517 olan ihracatçı firma sayısı, 2013 yılında 1427'ye yükselmiştir. İhracat yapan firma sayısının artışına paralel olarak ihracat değeri de artmış; 2002 yılında 130 milyon dolar olan ihracat 2013 yılında 1,4 milyar dolar olmuştur. $\mathrm{Bu}$ ihracatın \%93'ü imalat sanayi tarafından gerçekleştirilmiştir. Ülke bazında dikkate alındığında zamanla farklılıklar ortaya çıkmış; Avrupa ülkelerinde yaşanan ekonomik sorunlardan dolayı 2008 y1lından itibaren ihracatın yönü Ortadoğu ve Asya ülkelerine dönmüştür. Bu kapsamda 2013 yılı verileri dikkate alındığında Konya'nın 167 ülkeye ihracat yaptığı tespit edilmiştir. Bunlardan en fazla ihracat yapılan ülke 236 milyon dolar ile Irak olmuştur. Illler bazında yapılan kıyaslamalarda ele alınan dönemde Konya'nın ihrac1 9,53 kat artarken, söz konusu artı̧̧ Adana'da 3,16, Denizli'de 3,03, Eskişehir'de 4,49, Gaziantep'te 9,52, Kahramanmaraş'ta 1,45 ve Kayseri'de 15,01 oranında olmuştur.

Konya'nın ithalat performansı incelendiğinde ise, 2002 yılında 431 olan ithalatçı firma sayısı, 2013 yılında 1106'ya yükselmiştir. Söz konusu firmalar tarafından yapılan toplam ithalat da yıllar itibariyle sürekli olarak artmış; 2002 yılında 161 milyon dolar olan ithalat, 2013 y1lında 1,23 milyar dolara yükselmiştir. İhracatta olduğu gibi ithalatta da ilk sırada imalat sanayisi almıştır. 2013 yılında toplam ithalat içerisinde imalat sanayisinin payı $\% 75$, tarım ve hayvancılık sektörünün payı ise $\% 20$ 'dir. Diğer taraftan 2002 y1lında 162 milyon dolar olan ithalat 2013 yılında 1.25 milyar dolara yükselmiştir. Ülke rakamları dikkate alındığında, Konya'nın en fazla ithalatı Rusya Federasyonundan gerçekleştirdiği görülmüştür. Bu ülkeyi yıllar itibariyle farklılık olmakla birlikte, Almanya ve Çin izlemiştir. İller açısından bir karşılaştırma yapıldığında ise, ele alınan 2002-2013 döneminde en yüksek ithalat artış1 9,12 kat ile Gaziantep’te gerçekleşmiştir. Gaziantep'i sırasıyla; Konya 6,59 kat, Denizli 6,36 kat, Kahramanmaraş 4,75 kat, Eskişehir 4,1 kat, Adana 3,44 kat ve Kayseri ili 3,3 katlık bir artışla takip etmiştir.

Son olarak Konya ekonomisinin dış ticaret dengesi incelendiğinde, bazı yıllarda diş ticaret dengesinin fazla, bazı yıllarda ise açık verdiği belirlenmiştir. Buna göre 2008, 2009, 2010, 2012 ve 2013 yıllarında ihracatın ithalatı karşılama oranı 1'in üzerinde, diğer yılar ise altında kalmıştır. Değerin 1'in üzerinde olması Konya ekonomisinin rekabet gücünün yüksek, altında olması ise düşük olduğuna işaret etmektedir. Konya'nın rekabet gücünde ortaya çıkan bu olumlu gelişmenin nedenleri arasında, Konya Ovası Projesi ve Yüksek Hızlı Tren Projesi gibi kamu yatırımlarına bağlı olarak bölgenin yatırımcılar açısından cazip hale gelmesi sayılabilir. 


\section{KAYNAKÇA}

ALTAY, Feyzullah (2013), Konya İhracat Analizi Dış Ticarete Yön Verecek (1), Yeni İpek Yolu Konya Ticaret Odası Dergisi, Sayı: 306, s.22-25.

BALASSA, Bela (1986), Policy Responses to Exogenous Shocks in Developing Countries, American Economic Review, 1986(5), s.75-78.

BUTSO (Burdur Ticaret ve Sanayi Odası) (2013), İthalatçı Firmaların İllere Göre Dağılımı, http://www.butso.org.tr/belgeler/veriler2014/ithalat_rakamlari_2002_2013.pdf, Erişim Tarihi: 18.02.2016.

COE, David T. ve Elhanan Helpman (1995), International R\&D Spillovers, NBER Working Paper, No. 4444.

ÇOBAN, Orhan (2015), İktisada Giriş, Atlas Akademi, Konya.

DENG, Keyu; Li, Yuhong; Wang, Xiaoyin (2009), An Empirical Study on the Contribution of Foreign Trade to the Economic Growth of Southwest Minority Region of China, Computational Intelligence and Software Engineering, CiSE 2009, International Conference on, 11-13 Dec, Wuhan China.

FRANKEL JEFFREY A. ve David Romer (1999), Does Trade Cause Growth?, American Economic Review, 89(3), s.379-399.

KADEŞ, Cenk (2014), 2014 Yılı Adana Dış Ticaret Raporu, http://www.adanato.org.tr/WebDosyalar/Yayinlar/Adana\%20D\%C4\%B1\%C5\%9F\%20Ticareti/ADTR_2015.pdf,

Erişim Tarihi: 18.02.2016.

KTO (Konya Ticaret Odası), (2013), Konya Ekonomisine Genel Bakış, www.kto.org.tr/d/file/1.-konya-ekonomisine-genel-bakis.doc, Erişim Tarihi: 18.02.2016.

KTO (Konya Ticaret Odası), (2014), Konya Ekonomi Raporu 2013, http://www.kto.org.tr/d/file/konyaekonomiraporu2013.pdf, Erişim Tarihi: 18.02.2016.

MUCUK, Mehmet ve Ali Akgün (2011), İhracat ve İthalat Arasındaki İlişkilerin Konya Ekonomisi Bağlamında Değerlendirilmesi, Üçüncü Yerel Ekonomiler Kongresi Bildiriler Kitab1, Konya, s.182-191.

SACHS, Jeffrey D. ve Andrew M. Warner (1995), Economic Reform and Process of Global Integration, Brookings Papers on Economic Activity, 26(1), s.1-118.

SOSB (Sivas Organize Sanayi Bölgesi) (2016), Dünya' da ve Türkiye'de OSB Uygulamaları, http://www.sivasosb.org.tr/index.php?option $=$ com_content\&view=article\&id=97\&Itemid=95, Erişim Tarihi: 18.02.2016.

SUN, Peng ve Almas Heshmati (2010), International Trade and its Effects on Economic Growth in China, IZA Discussion Paper No. 5151, Bonn, Germany.
ŞAHBAZ,
Ussal
(2011),
Türkiye'nin
OSB
Deneyimi, http://www.tepav.org.tr/upload/files/haber/1298561949-2.Turkiye nin_OSB Deneyimi.pdf, Erişim tarihi: 18.02.2016.

TİM (Türkiye İhracatçılar Meclisi) (2015), 2001-2013 İhracat ve İhracat Rakamları, http://www.tim.org.tr/tr/ihracat-ihracat-rakamlari-tablolar.html, Erişim tarihi: 09.10.2015.

TÜIKK (Türkiye İstatistik Kurumu) (2013), Seçilmiş Göstergelerle Konya 2013, Ankara: TÜIKK Yayını, Yayın No: 4228.

TÜIKK (Türkiye İstatistik Kurumu) (2015), Dış Ticaret İstatistikleri, http://www.tuik.gov.tr/, Erişim Tarihi: 10.11.2015. 